\title{
Technical note: Quantification of lignans in the urine, milk, and plasma of flaxseed cake-fed dairy sheep
}

\author{
Cong-Cong Zhuang, ${ }^{1,2} \odot$ Xu Feng, ${ }^{1,2} \oplus$ Hai-Yan Xu, ${ }^{1,2} \odot$ Li Zhang, ${ }^{1} \odot$ Ling Liu, ${ }^{3} \odot$ Gong Zhang, ${ }^{4} \odot$ \\ Zhong Zheng, ${ }^{1 *}$ (1) and Chao-Mei $\mathrm{Ma}^{1,2 *}$ (1) \\ ${ }^{1}$ State Key Laboratory of Reproductive Regulation and Breeding of Grassland Livestock, School of Life Sciences, Inner Mongolia University, \\ Hohhot, P. R. China 010070 \\ ${ }^{2}$ Key Laboratory of Forage and Endemic Crop Biotechnology of Ministry of Education, School of Life Sciences, Inner Mongolia University, Hohhot, \\ P. R. China 010070 \\ ${ }^{3}$ Inner Mongolia Yishanyuan Biotechnology Co., Ltd., Hohhot, P. R. China 010111 \\ ${ }^{4}$ Mengtianran Animal Husbandry Technical Development Co., Ltd., Ulanqab, P. R. China 012207
}

\section{ABSTRACT}

Mammalian lignans are phytoestrogens with important bioactivities, and their concentrations in livestock milk may influence the health of consumers. This research aimed to establish a method to quantify multiple mammalian lignans in the biofluids of dairy sheep using ultra-HPLC-triple quadropole mass spectrometry with multiple-reaction monitoring. Secoisolariciresinol, 2-[(4-hydroxy-3-methoxyphenyl) methyl]-3-[(3-hydroxyphenyl)methyl]-1,4-butanediol, enterodiol (ED), enterolactone (EL), ED-sulfate (ED$\mathrm{S}$ ), and EL-sulfate (EL-S) were purified from the urine of flaxseed cake-fed dairy sheep. The structures of these lignans were identified by a combination of mass and nuclear magnetic resonance spectra. These purified lignans were used as standards to optimize their quantification conditions in urine, milk, and plasma of dairy sheep. On this basis, the lignan metabolites in biofluids were quantified. To improve analysis sensitivity, plasma and milk were pretreated with acetonitrile containing $1 \%$ formic acid and passed through a HybridSPE-PL 55261-U column (Supelco, Bellefonte, PA). The limit of quantification of the lignans ranged from 1.43 to 18.3 $\mathrm{ng} / \mathrm{mL}$ in plasma, and from 1.01 to $18.7 \mathrm{ng} / \mathrm{mL}$ in milk. The linearity of the calibration curves ranged from their limit of quantification to at least $217 \mathrm{ng} / \mathrm{mL}$ in plasma, and $217 \mathrm{ng} / \mathrm{mL}$ in milk. Regression coefficient of the calibration curves were above 0.99 for secoisolariciresinol, 2-[(4-hydroxy-3-methoxyphenyl)methyl]-3-[(3hydroxyphenyl)methyl]-1,4-butanediol, ED, EL, ED-S, and EL-S, indicating satisfactory relationships between the peak areas and concentrations in the quantification

\footnotetext{
Received March 4, 2020.

Accepted September 1, 2020.

*Corresponding authors: cmma@imu.edu.cn and zhengzhong@imu edu.cn
}

range. The relative concentrations of ED-glucuronide and EL-glucuronide (EL-G) in different biofluids were compared based on their chromatogram peak areas. The sheep plasma contained all forms of mammalian lignans (i.e., ED, EL, ED-S, EL-S, ED-glucuronide, and EL-G.); the urine contained ED, EL, ED-S, and EL-S; and the milk contained ED, EL, ED-S, EL-S, and EL-G. Milk-to-plasma concentration ratios of the mammalian lignans indicated that the free forms were more permeable than the sulfated conjugates. Mammalian lignans found in sheep plasma and milk may provide health benefits to the sheep and sheep-product consumers. The analytical method established in this work could be used to quantify mammalian lignans in livestock products.

Key words: linseed, livestock, milk, mammalian lignan

\section{Technical Note}

Flaxseed oil is an important source of n-3 fatty acids and is used in large quantities by the oil industry worldwide every year (Brühl et al., 2008). Flaxseed cake, which is the residue that remains following oil extraction, is rich in lignans that can be biotransformed in vivo and in vitro with the involvement of gut bacteria to form secoisolariciresinol (SECO), 2-[(4-hydroxy-3-methoxyphenyl)methyl]-3-[(3-hydroxyphenyl) methyl]-1,4-butanediol (PPB), enterodiol (ED), and enterolactone (EL) through hydrolysis and deglycosidation (Eeckhaut et al., 2008), demethylation (Jin and Hattori, 2010), dehydroxylation (Jin et al., 2007a), and oxidation and lactonization (Wang et al., 2000; Jin et al., 2007b; Gaya et al., 2016a). In mammalian urine and plasma, lignans are usually found as their conjugates, such as ED-sulfate (ED-S), EL-sulfate (EL-S), ED-glucuronide (ED-G), and EL-glucuronide (EL-G; Axelson and Setchell, 1980; Adlercreutz et al., 1993). Elevated levels of plasma mammalian lignans are as- 
sociated with reduced risks of colorectal adenoma (Kuijsten et al., 2006), acute coronary events (Vanharanta et al., 1999), and deaths related to cardiovascular disease (Vanharanta et al., 2003). The mammalian lignan could be well absorbed by dairy calves when fed with EL-enriched milk, suggesting that humans may also get potential health benefits by consuming milk enriched with mammalian lignans (Ghedini et al., 2017). Quantification of mammalian lignans in livestock milk and plasma is thus important to monitor the quality of livestock products.

Methods using HPLC and GC have been used to qualitatively and quantitatively analyze ED and EL in mammalian blood, urine, and other biomedia (Adlercreutz et al., 1993; Nørskov et al., 2015; Gaya et al. 2016b). Mammalian lignans are usually analyzed in their free forms, in which the glucuronidated and sulfated conjugates are hydrolyzed with glucuronidase and sulfatase before analysis. These analytical methods and associated results represent useful tools and information that can be used to monitor and investigate the metabolic routes of lignans, the relationship between mammalian lignans and health status, and the value of the milk and meat obtained from livestock that was fed different types and ratios of lignan-containing forage and flaxseed meal (Petit and Gagnon, 2009a,b; Bolca et al., 2010; Otero et al., 2018; Brito and Zang, 2019). An HPLC-mass method for direct quantification of EL, as well as its glucuronidated and sulfated conjugates, in human plasma using synthesized standards was recently reported (Nørskov et al., 2016). Direct quantification of the conjugated lignans may reflect the concentrations of the actual forms (e.g., EL-G, EL-S) of these mammalian lignans in plasma. It was reported that sheep had a greater conjugation capacity than cattle (Lundh,1990; Brito and Zang, 2019). Therefore, it is worth investigating the conjugated forms (i.e., glucuronidated and sulfated conjugates) of mammalian lignans in dairy sheep. This research was designed to isolate and purify free and conjugated forms of mammalian lignans from the urine of flaxseed cake-fed sheep and identify the structures with MS and nuclear magnetic resonance (NMR) spectra, and to use these lignans as standards for establishing an analytical method for quantification of multiple lignan metabolites in sheep milk and plasma. We then optimized the sample pretreatment procedure and quantification conditions and established an ultra HPLC (UHPLC)-triple quadropole MS in multiplereaction-monitory (MRM) mode using both precursor and characteristic product ions to sensitively quantify mammalian lignans in sheep biofluids.

The flaxseed cake was obtained from Yishanyuan Biotechnology Co., Ltd. (Hohhot, China) where the flaxseed was cold-pressed and yielded a residue con- taining higher concentration of ether extract $(10.9 \%$, Supplemental Table S1, https://doi.org/10.3168/jds .2020-18470) than flaxseed meals ( $<3 \%$; Brito et al., 2015; De Marchi et al., 2017). The experiments on dairy sheep were approved by the animal experimental ethics review committee of Inner Mongolia University ([2018]009) and carried out in accordance with Chinese laws and guidelines about animal welfare and handling. Collection of sheep milk, urine, and plasma were performed in Mengtianran dairy sheep experimental base (manager, Gong Zhang; location, Ulanqab, China) of State Key Laboratory of Reproductive Regulation and Breeding of Grassland Livestock, Inner Mongolia University, China. Two-year-old dairy ewes with the breed name DairyMeade were used. The ewes were fully housed indoors in groups of 40 to 50 ewes before the experiment and provided with TMR (for the ingredient and nutritional composition, see Supplemental Table S1, https://doi.org/10.3168/jds.2020-18470) twice a day for at least 2 mo.

Three ewes $(72.7 \pm 2.5 \mathrm{DIM}$ and $83.8 \pm 1.4 \mathrm{~kg}$ of BW) were randomly selected from the flock and transferred into $2-\mathrm{m}^{2}$ individual cages and fed separately. After being kept in the cages for $12 \mathrm{~h}$, the urine, blood, and milk samples were collected from each ewe as control group $(0 \mathrm{~h})$. A suspension of $250 \mathrm{~g}$ of fresh flaxseed cake in $1,000 \mathrm{~mL}$ of water was then gavaged to each ewe to ensure that the flaxseed cake was fully taken in a short time to allow for monitoring the concentration changes of mammalian lignans in different biofluid with time. The ewes were provided with clean water at all times. The milk and urine samples were collected at 12, 24, and $36 \mathrm{~h}$. The blood samples ( $5 \mathrm{~mL}$ each) were collected from the jugular vein at $1,2,4,8,12,18$, 24, 30, and $36 \mathrm{~h}$ with EDTAK $_{2}$ (EDTA dipotassium salt-coated)-Vacutainer tubes. The end point was set at $36 \mathrm{~h}$ to avoid the influence of longer fasting time on the physiology status of the ewes. The plasma was then separated from the blood by centrifugation $(6,708$ $\times g$ for $5 \mathrm{~min}$ at $4^{\circ} \mathrm{C}$ ) and then transferred to new tubes. Samples were numbered and stored at $-20^{\circ} \mathrm{C}$ until analysis.

All sheep urine was subjected to Buchner suction filtration, and the filtrate was concentrated to small volume under vacuum and chromatographed on octadecyl silane (38-63 $\mu \mathrm{m}$, Wako Pure Chemical Industries, Ltd. Richmond, VA), Sephadex LH20 (GE Healthcare Bio-Sciences AB, Uppsala, Sweden), and HPLC with an octadecyl silane $(20 \mathrm{~mm} \times 200 \mathrm{~mm})$ or Primesep P column $(10 \mathrm{~mm} \times 250 \mathrm{~mm})$ eluted with $\mathrm{H}_{2} \mathrm{O}$-methanol to obtain SECO, PPB, ED, EL, ED-S, and EL-S. The purity of these compounds was greater than $95.0 \%$ based on UHPLC-MS, and their structures were identified by MS and NMR spectra obtained with 
a Bruker Avance III 600 spectrometer (Bruker, Bremen, Germany).

Different solvent addition (methanol, ethanol, and acetonitrile) and pretreatments were tested to precipitate proteins for sensitive quantification of the lignans, and addition of $1 \%$ formic acid in $\mathrm{CH}_{3} \mathrm{CN}$ followed by a HybridSPE-PL 55261-U (Supelco, Bellefonte, PA) column treatment was found to be the best. One milliliter of the plasma or milk was treated with 3 -fold volume of $\mathrm{CH}_{3} \mathrm{CN}$ containing $1 \%$ formic acid, vortexed for 1 min, and centrifuged at $1,225 \times g$ for $5 \mathrm{~min}$ at $4^{\circ} \mathrm{C}$. The supernatant was passed through a HybridSPE-PL 55261-U (bed weight $30 \mathrm{mg}$ ) column. The procedure was repeated, and the combined eluate was dried with a rotating vacuum evaporator. The residue was redissolved in $250 \mu \mathrm{L}$ of methanol and passed through a $0.22-\mu \mathrm{m}$ filter. The filtrate was analyzed with an UHPLC (Agilent 1290 Infinity, Santa Clara, CA)-triple quadropole (Agilent 6430) with MRM at optimized conditions as listed in Table 1. The analysis column was an Agilent ZORBAX Eclipse Plus rapid resolution high definition C18 (octadecyl silane) column $(2.1 \times$ $50 \mathrm{~mm}, 1.8 \mu \mathrm{m})$. An autosampler was set at an injection volume of $2 \mu \mathrm{L}$. The mobile phase (composed of HPLC-grade solvents from Thermo Fisher Scientific, Waltham, MA) ran with a flow rate of $0.3 \mathrm{~mL} / \mathrm{min}$ and a program containing varying percentages ( $\mathrm{vol} / \mathrm{vol}$ ) of methanol in $0.1 \%$ aqueous formic acid as follows: 0 to 4 $\mathrm{min}, 40$ to $40 \%$; 4 to $7.5 \mathrm{~min}, 40$ to $45 \%$; 7.5 to $8 \mathrm{~min}$, 45 to $48 \%$; 8 to 9 min, 48 to $100 \%$; 9 to $11 \mathrm{~min}, 100 \%$. Negative MS mode was used for detection with capillary $3 \mathrm{kV}$, gas temperature at $325^{\circ} \mathrm{C}$, gas flow at $12 \mathrm{~L} /$ min, and nebulizer at $40 \mathrm{psi}$.

Chromatographic peaks were identified and confirmed by comparison with standards of their masscharge ratio $(m / z)$ values, retention times, and UV spectra. Quantification was performed using an external standard method with MRM analysis of the standards at 9 concentrations from $0.219 \mathrm{ng} / \mathrm{mL}$ to $55.6 \mu \mathrm{g} / \mathrm{mL}$ for the calibration curves (Supplemental Tables S2-4, https://doi.org/10.3168/jds.2020-18470). Calibration solutions were prepared in the respective matrix (plasma or milk) and pretreated using the same procedure as for the samples. Each sample was analyzed 3 times and represented as the means and standard deviations. Limit of detection and limit of quantification (LOQ) were determined as the concentrations where the signal-to-noise ratios were 3 and 10 times, respectively. The concentrations of free mammalian lignans and their sulfated conjugates in biofluids were statistically analyzed with SAS STAT software (version 9.4; SAS Institute Inc., Cary, NC), and statistical significance was assessed by the 2-tailed, unpaired Student's $t$-test.

We structurally identified SECO, PPB, ED, and EL by comparison of their NMR and MS data with those previously reported (Wang et al., 2000). Both ED and EL displayed a product ion at $m / z 253$ in the negative ionization mode, corresponding to the loss of a $\mathrm{H}_{2}$ and a formic acid from ED, and the loss of a carbon dioxide from EL. The ED-S and EL-S with pseudomolecular ions at $m / z 381$ and 377 , respectively, showed product ions at $m / z 301$ and 297 , characteristic for the loss of a sulfuric acid $[\mathrm{M}-80-\mathrm{H}]^{-}$to form ED and EL, indicating they were the sulfated mammalian lignans. The structures of ED-S and EL-S were further confirmed by NMR. The ED-G and EL-G with $[\mathrm{M}-\mathrm{H}]^{-} 477$ and 473 , respectively, showed product ions of $[\mathrm{M}-176-\mathrm{H}]^{-}$at $m / z 301$ and 297, corresponding to the loss of a glucuronic acid to form ED and EL, respectively, indicating they were the glucuronidated mammalian lignans. The characteristic product ions of these lignans were used in combination with their precursor ions as important parameters (Table 1) in UHPLC-MS-MRM to sensitively and selectively quantify these lignans.

The LOQ of the lignans ranged from 1.43 to $18.3 \mathrm{ng} /$ $\mathrm{mL}$ in plasma, and 1.01 to $18.7 \mathrm{ng} / \mathrm{mL}$ in milk. The linearity of the lignans ranged from their LOQ to at least $217 \mathrm{ng} / \mathrm{mL}$ in plasma, and $217 \mathrm{ng} / \mathrm{mL}$ in milk. Linear regression coefficient of the peak areas versus concentrations in the quantification range were above 0.99 for

Table 1. The optimized multiple-reaction monitory condition for quantification of the lignans

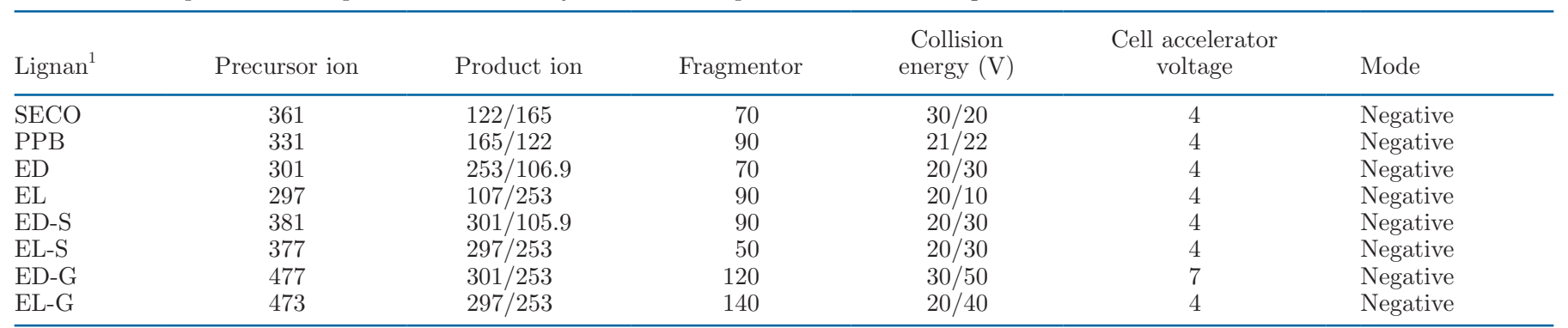

${ }^{1} \mathrm{SECO}=$ secoisolariciresinol; PPB = 2-[(4-hydroxy-3-methoxyphenyl)methyl]-3-[(3-hydroxyphenyl)methyl]-1,4-butanediol; ED = enterodiol; EL $=$ enterolactone; ED-S = ED-sulfate; EL-S = EL-sulfate; ED-G = ED-glucuronide; EL-G = EL-glucuronide. 
Table 2. Milk-to-plasma concentration ratios of the lignans at their peaking time

\begin{tabular}{lccc}
\hline Lignan $^{1}$ & Milk concentration $(\mathrm{ng} / \mathrm{mL})$ & Plasma concentration $(\mathrm{ng} / \mathrm{mL})$ & Ratio \\
\hline SECO & $\mathrm{NQ}^{2}$ & $\mathrm{NQ}$ & $\mathrm{NA}^{3}$ \\
PPB & $\mathrm{NQ}$ & $\mathrm{NQ}$ & $\mathrm{NA}^{*}$ \\
ED & 2.68 & 6.43 & $41.7 \%^{*}$ \\
EL & 29.19 & 66.08 & $44.2 \%^{*}$ \\
ED-S & 20.01 & 197.46 & $10.1 \%$ \\
EL-S & 213.76 & $1,410.17$ & $15.2 \%$ \\
ED-G & $\mathrm{NQ}$ & 295.50 & $\mathrm{NA}$ \\
EL-G & 361.50 & $17,835.00$ & $2.03 \%$ \\
\hline
\end{tabular}

${ }^{1} \mathrm{SECO}=$ secoisolariciresinol; PPB = 2-[(4-hydroxy-3-methoxyphenyl)methyl]-3-[(3-hydroxyphenyl)methyl]-1,4butanediol; $\mathrm{ED}=$ enterodiol; $\mathrm{EL}=$ enterolactone; $\mathrm{ED}-\mathrm{S}=\mathrm{ED}$-sulfate; EL-S = EL-sulfate; $\mathrm{ED}-\mathrm{G}=\mathrm{ED}-$ glucuronide; EL-G = EL-glucuronide.

${ }^{2} \mathrm{NQ}=$ not quantified because the concentration was below the quantification limit.

${ }^{3} \mathrm{NA}=$ not applicable.

${ }^{4}$ Chromatogram peak areas were used to represent the relative concentrations as there were no standards for these 2 lignans.

${ }^{*} P<0.05$, for free mammalian lignans ED and EL to compare with their sulfated conjugates ED-S and EL-S, respectively.

SECO, PPB, ED, EL, ED-S, and EL-S (Supplemental Tables S2-4, https://doi.org/10.3168/jds.2020-18470). As there were not enough pure standards for calibration for ED-G and EL-G, the relative concentrations of these 2 compounds were compared by their peak areas in the UHPLC-MS chromatograms.

We detected SECO, PPB, ED, EL, ED-S, and EL-S in the sheep urine (Supplemental Figure S1, https:/ /doi.org/10.3168/jds.2020-18470), and they reached peak concentrations at $12 \mathrm{~h}$ after the sheep fed with flaxseed cake. The EL, ED, and their conjugates were all detected in plasma (Supplemental Figure S2, https: //doi.org/10.3168/jds.2020-18470) and they reached peak concentrations at 4 to $8 \mathrm{~h}$. The EL, ED, EL-G, EL-S, and ED-S were detected in the milk, while ED-G was not (Supplemental Figure S3, https://doi.org/10 $.3168 /$ jds.2020-18470). They reached peak concentrations at $12 \mathrm{~h}$ or later in the milk.

Mammalian lignans are widely accepted to be the metabolites of plant lignans and are commonly found in mammalian urine and plasma (Setchell et al., 1980; Axelson et al., 1982; Nørskov et al., 2015). Mammalian lignans in livestock milk have received increased interest over the past 2 decades because milk is consumed by most of the world's population, and demand for milk is increasing (Brito and Zang, 2019). Most previous investigations detected EL (Petit et al., 2009; Lima, et al., 2016; Ghedini, et al., 2018), and other studies also detected ED in dairy cow milk (Petit and Gagnon, 2009a,b). To the best of our knowledge, our work is the first to report the presence of conjugated mammalian lignans (ED-S, EL-S, EL-G) in dairy sheep milk. A longer period of time $(>8 \mathrm{~h})$ was required for these compounds to reach their maximum milk con- centrations as compared with their maximum blood concentrations. The concentrations of these lignans in milk was less than their concentrations in plasma at their peak time, indicating that the blood-milk barrier blocked some of the lignans. The blood-milk barrier formed by tight junctions of mammary epithelial cells selectively permits some components in the circulation to be taken up by the mammary gland (Tsugami et al., 2017). Based on the ratios of milk-to-plasma concentration of these compounds at their peak time (Table 2), larger concentrations of free mammalian lignans (ED and EL) passed the blood-milk barrier as compared with the sulfated conjugates (ED-S and EL-S). It is reported that ABCG2 (the ATP-binding cassette transporter G2) was responsible for the secretion of EL into milk (Miguel et al., 2014; Otero et al., 2016). Further research is needed to elucidate whether and how the high-polar lignans, ED-S and EL-S, are actively secreted to milk by ABCG2.

Animals in the present study received flaxseed cake via gavage in a water suspension, which might have resulted in some flaxseed bypassing the rumen and shifting fermentation to the large intestine. It is worth noting that some adult ruminants may maintain a functional esophageal groove; a small amount of soluble feeds can thus bypass the rumen (Woodford et al., 1984; Hofmann 1989). However, the esophageal groove reflex could be influenced by many factors, and in adult ruminants the occurrence probability of rumen bypass is low (Sargison et al., 1998; Lechner et al., 2009).

In conclusion, the present research established a new methodology (UHPLC-MS-MRM) to quantify lignanderived metabolites in different biofluids. The method sensitively quantified free and conjugated mammalian 
lignans in dairy sheep plasma and milk, providing a useful tool for monitory mammalian lignans in livestock products.

\section{ACKNOWLEDGMENTS}

This research was supported by the Science and Technology Major Project of Inner Mongolia Autonomous Region of China to the State Key Laboratory of Reproductive Regulation and Breeding of Grassland Livestock (ZDZX2018065; Hohhot, China), the Science and Technology Program of Inner Mongolia Autonomous Region of China to Chao-Mei Ma (2019GG247; Hohhot, China), and the Inner Mongolia Scientific and Technological Innovation, Leading \& Reward Fund to Li Zhang (30500-5173203; Hohhot, China). We thank Liwei Wang, Chengbin Shan, and Mengda Shen for giving assistance in collecting sheep plasma and urine samples. The authors declare that there are no conflicts of interest.

\section{REFERENCES}

Adlercreutz, H., T. Fotsis, J. Lampe, K. Wahala, T. Makela, G. Brunow, and T. Hase. 1993. Quantitative-determination of lignans and isoflavonoids in plasma of omnivorous and vegetarian women by isotope-dilution gas-chromatography mass-spectrometry. Scand. J. Clin. Lab. Invest. Suppl. 215:5-18. https://doi.org/10.3109/ 00365519309090693.

Axelson, M., and K. D. R. Setchell. 1980. Conjugation of lignans in human-urine. FEBS Lett. 122:49-53. https://doi.org/10.1016/ 0014-5793(80)80399-1.

Axelson, M., J. Sjövall, B. E. Gustafsson, and K. D. R. Setchell. 1982. Origin of lignans in mammals and identification of a precursor from plants. Nature 298:659-660. https://doi.org/10.1038/298659a0.

Bolca, S., M. Urpi-Sarda, P. Blondeel, N. Roche, L. Vanhaecke, S. Possemiers, N. Al-Maharik, N. Botting, D. De Keukeleire, M. Bracke, A. Heyerick, C. Manach, and H. Depypere. 2010. Disposition of soy isoflavones in normal human breast tissue. Am. J. Clin. Nutr. 91:976-984. https://doi.org/10.3945/ajcn.2009.28854.

Brito, A. F., H. V. Petit, A. B. D. Pereira, K. J. Soder, and S. Ross. 2015. Interactions of corn meal or molasses with a soybean-sunflower meal mix or flaxseed meal on production, milk fatty acid composition, and nutrient utilization in dairy cows fed grass haybased diets. J. Dairy Sci. 98:443-457. https://doi.org/10.3168/jds .2014-8353.

Brito, A. F., and Y. Zang. 2019. A Review of Lignan metabolism, milk enterolactone concentration, and antioxidant status of dairy cows fed flaxseed. Molecules 24:41. https://doi.org/10.3390/ molecules24010041.

Brühl, L., B. Matthäus, A. Scheipers, and T. Hofmann. 2008. Bitter off-taste in stored cold-pressed linseed oil obtained from different varieties. Eur. J. Lipid Sci. Technol. 110:625-631. https://doi.org/ 10.1002 /ejlt.200700314.

De Marchi, F. E., G. T. Santos, H. V. Petit, and C. Benchaar. 2017. Oxidative status of dairy cows fed flax meal and infused with sunflower oil in the abomasum. Anim. Feed Sci. Technol. 228:115-122. https://doi.org/10.1016/j.anifeedsci.2017.04.013.

Eeckhaut, E., K. Struijs, S. Possemiers, J. P. Vincken, D. De Keukeleire, and W. Verstraete. 2008. Metabolism of the lignan macromolecule into enterolignans in the gastrointestinal lumen as determined in the simulator of the human intestinal microbial ecosystem. J. Agric. Food Chem. 56:4806-4812. https://doi.org/ $10.1021 /$ jf800101s.
Gaya, P., J. L. Arqués, M. Medina, I. Álvarez, and J. M. Landete. 2016b. A new HPLC-PAD/HPLC-ESI-MS method for the analysis of phytoestrogens produced by bacterial metabolism. Food Anal. Methods 9:537-547. https://doi.org/10.1007/s12161-015-0226-3.

Gaya, P., M. Medina, A. Sánchez-Jiménez, and J. M. Landete. 2016a. Phytoestrogen metabolism by adult human gut microbiota. Molecules 21:1034. https://doi.org/10.3390/molecules21081034.

Ghedini, C. P., D. C. Moura, R. A. V. Santana, A. S. Oliveira, and A. F. Brito. 2018. Replacing ground corn with incremental amounts of liquid molasses does not change milk enterolactone but decreases production in dairy cows fed flaxseed meal. J. Dairy Sci. 101:2096-2109. https://doi.org/10.3168/jds.2017-13689.

Ghedini, C. P., N. L. Whitehouse, D. C. Moura, A. S. Oliveira, and A. F. Brito. 2017. The mammalian lignan enterolactone is absorbed by newborn dairy calves fed enterolactone-enriched milk. J. Dairy Sci. 100:8170-8175. https://doi.org/10.3168/jds.2017-13093.

Hofmann, R. R. 1989. Evolutionary steps of ecophysiological adaptation and diversification of ruminants: A comparative view of their digestive system. Oecologia 78:443-457. https://doi.org/10.1007/ BF00378733.

Jin, J. S., and M. Hattori. 2010. Human intestinal bacterium, strain END-2 is responsible for demethylation as well as lactonization during plant lignan metabolism. Biol. Pharm. Bull. 33:1443-1447. https://doi.org/10.1248/bpb.33.1443.

Jin, J. S., N. Kakiuchi, and M. Hattori. 2007b. Enantioselective oxidation of enterodiol to enterolactone by human intestinal bacteria. Biol. Pharm. Bull. 30:2204-2206. https://doi.org/10.1248/bpb.30 .2204 .

Jin, J. S., Y. F. Zhao, N. Nakamura, T. Akao, N. Kakiuchi, B. S. Min, and M. Hattori. 2007a. Enantioselective dehydroxylation of enterodiol and enterolactone precursors by human intestinal bacteria. Biol. Pharm. Bull. 30:2113-2119. https://doi.org/10.1248/ bpb.30.2113.

Kuijsten, A., I. C. W. Arts, P. C. H. Hollman, P. van't Veer, and E. Kampman. 2006. Plasma enterolignans are associated with lower colorectal adenoma risk. Cancer Epidemiol. Biomarkers Prev. 15:1132-1136. https://doi.org/10.1158/1055-9965.EPI-05-0991.

Lechner, I., P. Barboza, W. Collins, D. Günther, B. Hattendorf, J. Hummel, and M. Clauss. 2009. No 'bypass' in adult ruminants: Passage of fluid ingested vs. fluid inserted into the rumen in fistulated muskoxen (Ovibos moschatus), reindeer (Rangifer tarandus) and moose (Alces alces). Comp. Biochem. Physiol. A Mol. Integr. Physiol. 154:151-156. https://doi.org/10.1016/j.cbpa.2009.05.122.

Lima, L. S., M. F. Palin, G. T. Santos, C. Benchaar, and H. V. Petit. 2016. Dietary flax meal and abomasal infusion of flax oil on microbial $\beta$-glucuronidase activity and concentration of enterolactone in ruminal fluid, plasma, urine and milk of dairy cows. Anim. Feed Sci. Technol. 215:85-91. https://doi.org/10.1016/j.anifeedsci.2016 .03.006.

Lundh, T. J. O. 1990. Conjugation of the plant estrogens formononetin and daidzein and their metabolite equol by gastrointestinal epithelium from cattle and sheep. J. Agric. Food Chem. 38:1012-1016. https://doi.org/10.1021/jf00094a021.

Miguel, V., J. A. Otero, R. Garcia-Villalba, F. Tomas-Barberan, J. C. Espin, G. Merino, and A. I. Alvarez. 2014. Role of ABCG2 in transport of the mammalian lignan enterolactone and its secretion into milk in Abcg2 knockout mice. Drug Metab. Dispos. 42:943946. https://doi.org/10.1124/dmd.113.055970.

Nørskov, N. P., C. Kyrø, A. Olsen, A. Tjønneland, and K. E. B. Knudsen. 2016. High-throughput LC-MS/MS method for direct quantification of glucuronidated, sulfated, and free enterolactone in human plasma. J. Proteome Res. 15:1051-1058. https://doi.org/10 .1021 /acs.jproteome.5b01117.

Nørskov, N. P., A. Olsen, A. Tjonneland, A. K. Bolvig, H. N. Laerke, and K. E. B. Knudsen. 2015. Targeted LC-MS/MS method for the quantitation of plant lignans and enterolignans in biofluids from humans and pigs. J. Agric. Food Chem. 63:6283-6292. https://doi .org/10.1021/acs.jafc.5b01275.

Otero, J. A., D. García-Mateos, I. Alvarez-Fernández, R. García-Villalba, J. C. Espín, A. I. Álvarez, and G. Merino. 2018. Flaxseedenriched diets change milk concentration of the antimicrobial 
danofloxacin in sheep. BMC Vet. Res. 14:14. https://doi.org/10 .1186/s12917-018-1341-3.

Otero, J. A., V. Miguel, L. González-Lobato, R. García-Villalba, J. C. Espín, J. G. Prieto, G. Merino, and A. I. Álvarez. 2016. Effect of bovine ABCG2 polymorphism Y581S SNP on secretion into milk of enterolactone, riboflavin and uric acid. Animal 10:238-247. https://doi.org/10.1017/S1751731115002141.

Petit, H. V., and N. Gagnon. 2009a. Milk concentrations of the mammalian lignans enterolactone and enterodiol, milk production, and whole tract digestibility of dairy cows fed diets containing different concentrations of flaxseed meal. Anim. Feed Sci. Technol. 152:103111. https://doi.org/10.1016/j.anifeedsci.2009.04.004.

Petit, H. V., and N. Gagnon. 2009b. Concentration of the mammalian lignans enterolactone and enterodiol in milk of cows fed diets containing different concentrations of whole flaxseed. Animal 3:1428-1435. https://doi.org/10.1017/S1751731109990346.

Petit, H. V., N. Gagnon, P. S. Mir, R. Cao, and S. Cui. 2009. Milk concentration of the mammalian lignan enterolactone, milk production, milk fatty acid profile, and digestibility in dairy cows fed diets containing whole flaxseed or flaxseed meal. J. Dairy Res. 76:257-264. https://doi.org/10.1017/S0022029909003999.

Sargison, N. D., K. J. Stafford, and D. M. West. 1998. The effects of age, weaning, drench volume and yarding on ruminoreticulum bypass in sheep, with reference to the anthelmintic efficacy of benzimidazole drenches. N. Z. Vet. J. 46:20-27. https://doi.org/10 $.1080 / 00480169.1998 .36045$.

Setchell, K. D., A. M. Lawson, F. L. Mitchell, H. Adlercreutz, D. N. Kirk, and M. Axelson. 1980. Lignans in man and in animal species. Nature 287:740-742. https://doi.org/10.1038/287740a0.

Tsugami, Y., K. Matsunaga, T. Suzuki, T. Nishimura, and K. Kobayashi. 2017. Phytoestrogens weaken the blood-milk barrier in lactating mammary epithelial cells by affecting tight junctions and cell viability. J. Agric. Food Chem. 65:11118-11124. https://doi .org/10.1021/acs.jafc.7b04786.
Vanharanta, M., S. Voutilainen, T. A. Lakka, M. van der Lee, H. Adlercreutz, and J. T. Salonen. 1999. Risk of acute coronary events according to serum concentrations of enterolactone: A prospective population-based case-control study. Lancet 354:2112-2115. https: //doi.org/10.1016/S0140-6736(99)05031-X.

Vanharanta, M., S. Voutilainen, T. H. Rissanen, H. Adlercreutz, and J. T. Salonen. 2003. Risk of cardiovascular disease-related and allcause death according to serum concentrations of enterolactone: Kuopio ischaemic heat disease risk factor study. Arch. Intern. Med. 163:1099-1104. https://doi.org/10.1001/archinte.163.9.1099.

Wang, L. Q., M. R. Meselhy, Y. Li, G. W. Qin, and M. Hattori. 2000. Human intestinal bacteria capable of transforming secoisolariciresinol diglucoside to mammalian lignans, enterodiol and enterolactone. Chem. Pharm. Bull. (Tokyo) 48:1606-1610. https://doi .org/10.1248/cpb.48.1606.

Woodford, S. T., M. R. Murphy, C. L. Davis, and K. R. Holmes. 1984. Ruminal bypass of drinking water in lactating cows. J. Dairy Sci. 67:2471-2474. https://doi.org/10.3168/jds.S0022-0302(84)81599 -4 .

\section{ORCIDS}

Cong-Cong Zhuang @ https://orcid.org/0000-0002-5911-7444 Xu Feng ๑ https://orcid.org/0000-0001-8257-7935

Hai-Yan Xu () https://orcid.org/0000-0002-7535-1353

Li Zhang ๑ https://orcid.org/0000-0003-0516-762X

Ling Liu ๑ https://orcid.org/0000-0001-6867-996X

Gong Zhang (1) https://orcid.org/0000-0002-2329-3462

Zhong Zheng ๑ https://orcid.org/0000-0001-5961-2122

Chao-Mei Ma $\odot$ https://orcid.org/0000-0003-1189-7901 